\title{
Conceptualizing dietary Westernization, observing dietary
} transitions

In this issue of Public Health Nutrition, Uusitalo et al. ${ }^{1}$ address the issue of how dietary Westernisation might be conceptualised in research. This is a novel question because we mostly believe that we already know what dietary Westernisation is. Many of us eat a Western-type meal every day, or we are surrounded by others who consume Western-type diets, or we experience Western diets vicariously through advertising industry images. In their study to conceptualise and measure dietary Westernisation, Uusitalo et al. make some interesting observations: that a relatively small number of indicator foods can be used to describe it in Mauritius, and that other dietary patterns may actually represent transitions towards Western patterns or away from traditional ones.

Their most interesting observation, however, regards the dynamic nature of dietary patterns. Their traditional pattern, for example, was correlated with intake of Indian breads, sauces and tea, but also with regular soft drinks and sugar added to tea. They suggest, in fact, that 'a pure indigenous dietary pattern with no Western foods in the diet may already be extinct in Mauritius'.

Historical examination shows that Western dietary patterns are not static either. The stereotypical US meal of red meat and potatoes is grounded in the British heritage that lies at the foundation of US culture ${ }^{2}$. But in the early part of the 20th century, with the rise of nutrition as a science, the growth of the food and advertising industries, and government-sponsored food conservation programs during World War I, a new dietary pattern emerged - one based on the concept that one should eat fruits and vegetables as a way to be healthy ${ }^{2}$. Both the meat-and-potatoes and fruits-and-vegetables patterns can fairly be labelled as 'Western'. In fact, these are the two dominant patterns that we see in factor analytical studies in US populations ${ }^{3-5}$. Aspects of both are seen in the Western dietary pattern in Mauritius as well ${ }^{1}$.

As Uusitalo et al. suggest, we need more detailed examinations of dietary transition and dietary Westernisation as separate entities. Their study raises questions to be addressed in future work: How should we measure traditional or Western patterns - empirically, using a statistical method such as principal components analysis, or using an index based on qualitative understanding of a prototypical diet? How do we recognise the emergence of new, real patterns in dietary data? And how well can crosssectional observations be extrapolated to the longitudinal process of dietary Westernisation?
In describing the phenomenon of dietary Westernisation, migrant studies provide another valuable perspective. Also in this issue of Public Health Nutrition is a paper by Heald et al., which shows marked differences in both dietary intake and the insulin-like growth (IGF) factor system between Gujarati Indians in India and those who migrated to the $\mathrm{UK}^{6}$. Their findings provide compelling evidence, in the tradition of migrant studies, that environmental factors - possibly dietary - play a major role in influencing the IGF system and hence in affecting chronic disease risk.

The special issue of Public Health Nutrition that accompanies this issue presents a new view of nutrition as a science - one that goes beyond biology and incorporates fields as disparate as economics and the social, political and environmental sciences. Certainly, social, economic and cultural changes lie at the heart of the process of dietary Westernisation. However, not atypically for our journal, the papers contained within the present regular issue also represent a sampling of topics falling at different corners of the new nutrition science - a review of isotope dilution techniques to assess vitamin A status ${ }^{7}$, the association of geographic area deprivation with childhood obesity ${ }^{8}$ and the contribution of drought in southern Africa to childhood malnutrition?. We look forward to discussions and to the development of a new conceptual framework to organise the scope of work falling within nutritional science, and to take our discipline to new directions ${ }^{10}$. Meanwhile, our work (whether as old nutritional scientists or as new ones) continues.

Marilyn Tseng

Editor

\section{References}

1 Uusitalo U, Sobal J, Moothoosamy L, Chitson P, Shaw J, Zimmet $\mathrm{P}$, et al. Dietary Westernisation: conceptualisation and measurement in Mauritius. Public Health Nutrition 2005; 8(6): 608-19.

2 Levenstein HA. Revolution at the Table: The Transformation of the American Diet. New York: Oxford University Press, 1988.

3 Slattery ML, Boucher KM, Caan BJ, Potter JD, Ma KN. Eating patterns and risk of colon cancer. American Journal of Epidemiology 1998; 148(1): 4-16.

4 Hu F, Rimm E, Smith-Warner S, Feskanich D, Stampfer MJ, Ascherio A, et al. Reproducibility and validity of dietary 
patterns assessed with a food-frequency questionnaire. American Journal of Clinical Nutrition 1999; 69(2): 243-9.

5 Tseng M, DeVellis RF. Fundamental dietary patterns and their correlates among US whites. Journal of the American Dietetics Association 2001; 101(8): 929-32.

6 Heald AH, Sharma R, Anderson SG, Vyas A, Siddals K, Patel J, et al. Dietary intake and the insulin-like growth factor system: effects of migration in two related populations in India and Britain with markedly different dietary intake. Public Health Nutrition 2005; 8(6): 620-7.

7 Furr HC, Green MH, Haskell M, Mokhtar N, Nestel P, Newton S, et al. Stable isotope dilution techniques for assessing vitamin A status and bioefficacy of provitamin A carotenoids in humans. Public Health Nutrition 2005; 8(6): 596-607.

8 Dummer TJB, Gibbon MA, Hackett AF, Stratton G, Taylor SR. Is overweight and obesity in 9-10-year-old children in Liverpool related to deprivation and/or electoral ward when based on school attended? Public Health Nutrition 2005; 8(6): 636-41.

9 Mason JB, Bailes A, Mason KE, Yambi O, Jonsson U, Hudspeth C, et al. AIDS, drought, and child malnutrition in southern Africa. Public Health Nutrition 2005; 8(6): 551-63.

10 Leitzmann C, Cannon G. Beginnings [Editorial]. Public Health Nutrition 2005; 8(6A): 669-70. 